\title{
Enabling customer co-creation behavior at a distance: the case of patients using self-monitoring handheld devices in healthcare
}

\author{
Le Nguyen $\mathrm{Hau}^{1}$ (D) Pham Ngoc Thuy ${ }^{2}$
}

Received: 25 September 2020 / Accepted: 28 June 2021 / Published online: 5 July 2021

(c) The Author(s), under exclusive licence to Springer-Verlag GmbH Germany, part of Springer Nature 2021

\begin{abstract}
The inherent feature of inseparability causes significant sufferings for the service sector. In the case of diabetes disease in healthcare, this problem is reduced by asking patients to self-monitor blood glucose at home (SMBG). Despite the task's importance, many patients do not fully accomplish. This study investigates what factors of patients affect their adherence to SMBG and how physician consultation fosters their adherence. Empirical results show that the adherence level is driven by patients' capability and self-efficacy, both of which are fostered by the knowledge acquired from physicians. These findings provide insights to support strategies to reduce the service inseparability.
\end{abstract}

Keywords Adherence - Consultation · Capability · Healthcare · Handheld Devices · Self-efficacy

\section{Introduction}

Nowadays, chronic diseases such as diabetes, hypertension, or heart-related diseases are on the rise worldwide due to population aging and changes in social behaviors. For treatment and management of these costly long-term health problems, healthcare professionals (i.e., service providers) need the most updated and real-time data about a patient's medical conditions. While the collection of these data is straightforward when being conducted on inpatients, the task is challenging when it comes to outpatients due to the spatial separation from nurses' assistance and specialized devices. In this situation, the advance in healthcare

Le Nguyen Hau

Lnhau@hcmut.edu.vn

1 School of Industrial Management, Ho Chi Minh City University of Technology, 268 Ly Thuong Kiet Str., Dist. 10, Ho Chi Minh City, Vietnam

2 Vietnam National University Ho Chi Minh City, Linh Trung Ward, Thu Duc District, Ho Chi Minh City, Vietnam 
technology has made the task possible. Many physicians recommend their outpatients to use wearable or handheld devices to self-monitor their health condition (i.e., blood pressure, blood glucose, heart pulse). This measure may not only improve the effectiveness of medical treatment but also significantly cut medical cost for patients (e.g., $21 \%$ to $36 \%$ in the USA, Yi et al. 2019). However, the use of self-monitoring medical devices at home is not without annoyance and challenge, which consequently results in a lower-than-expected rate of adherence to using these devices. Taking the case of diabetes, studies revealed that the adherence rate was only $62 \%$ in Spain, $49 \%$ in the USA, $44 \%$ in Sweden, and $28 \%$ in China (Florc et al. 2018; Moström et al. 2017; Wang et al. 2019; Yi et al. 2019). This phenomenon has called for scholarly endeavors to understand the drivers of the adherence and the role of healthcare providers in improving the situation.

In medical research, a review of literature has indicated that factors hindering the regular use of self-monitoring devices include patient's psychological state such as pain, fear, discomfort, frustration, or lack of resources such as knowledge, skill, time, or finance (Wang et al. 2019). Prior studies have also found that physicians can improve the patient's adherence by measures such as educating, motivating, close monitoring, and counseling (Yi et al. 2019). However, insights into the mechanism of effect among these factors have not been fully elucidated in the extant literature (Anderson et al. 2016; Tikkanen 2020).

In view of the service-dominant logic (SDL_Vargo and Lusch 2016), a healthcare service is co-created by different actors including provider (e.g., physician) and customer (e.g., patient). Each of them needs to perform certain interaction behaviors, which collaboratively transform their contributed resources into the service benefits. In the phenomenon described above, when a physician recommends a patient to do the self-monitoring blood glucose (SMBG) at home, the interaction platform for co-creation is extended from the provider's face-toface encounter to the patient's own sphere (Gronroos and Voima 2013). In this extended platform, the patient is empowered to perform the task on behalf of the healthcare professional. As such, the responsibility for this co-creation task is shifted to the customer who has the full autonomy for the task. However, as mentioned above, not all customers are ready to assume this responsibility, despite the benefits resulted from this co-creation activity (Anderson et al. 2016). Literature has suggested that the fulfillment of extended co-creation activities requires certain conditions on the customer including the ability and the confidence to perform the task (Bettencourt et al. 2002). However, the question about how these factors work in this specific service setting has yet been fully answered (OseiFrimpong et al. 2020; Tikkanen 2020). Moreover, prior studies have emphasized the role of service frontliners in activating customer co-creation (Hau et al. 2017); the next question is how and to what extent the specialized knowledge and motivation received by customers (patients) from service frontliners (physicians) through the consultation process (in this study, we use the term physician consultation for short) can help customers to fulfill the co-creation task in their own sphere. In this respect, several terms have been provided in the literature such as physician consultation, customer empowerment, enablement, activation, involvement, engagement, and participation. However, empirical studies to provide 
evidence about the effects of these factors are still limited (Davey and Grönroos 2019; Seiders et al. 2015; Hau et al. 2017).

To address this problem, the present study has a twofold objective: The first objective is to identify the impact of physician's consultation on patient's capability and self-efficacy in performing the self-monitoring task. The second objective is to examine the effects of patient's capability and self-efficacy on his or her adherence to SMBG. Regarding the research setting, the empirical context for this study is the healthcare service for diabetes patients. In the management of this chronic disease, patients are recommended to use a handheld device regularly at home for SMBG. This task is necessary to navigate regimen and detect hypoglycemia adverse event. Although testing blood glucose by it does not change glucose level, it provides realtime information about glucose fluctuation which is critical to navigate therapy (International Diabetes Federation-IDF 2020).

By achieving these research objectives, this study contributes to the literature in three aspects. The first contribution relates to the inherent features of inseparability and high contact of several services including healthcare. In many situations, particularly in the current COVID-19 crisis, these features cause serious suffering for the service sector worldwide. In the pandemic, the sector faces a big challenge in which multiple forms of face-to-face contact between co-creation actors can lead to serious illness or death (Berry et al. 2020). In this regard, this study provides evidence to promote a measure to increase the separability and decrease direct contacts in services, which has been termed "untact" strategy in services (Lee and Lee 2020). This strategy can be implemented by encouraging service providers to apply technology-based innovations characterized by spatial flexibility and social outreach into their service procedure (Heinonen and Strandvik 2020). The second contribution regards to the enrichment of SDL theory. This study provides a case in which the service co-creation platform is extended beyond the direct interaction encounter to customers' own sphere. This extended platform creates more opportunities and flexibilities for better co-creation mechanisms between service providers and customers. The third contribution of this study is to provide more insights into the trend of shifting part of the responsibility from conventional healthcare providers to customers so that customers can actively manage their own health and life (Anderson et al. 2016). This shift has raised concerns and challenges because customers vary substantially in terms of health service literacy (Davey and Grönroos 2019). They are certainly unable to decently complete the co-creation job without relevant support from the health service providers. In this respect, our findings suggest that the responsibilization process must go hand in hand with appropriate measures to improve customer capability through activities like consultation, education, enablement, or capabilization.

The remaining sections of this paper are structured as follows: The next section presents the background for constructs in this study including SDL, physician consultation, patient adherence, patient capability, and patient self-efficacy. After that, the theoretical justification for each of the five hypotheses and the proposed research model are presented. Then, we report the research method, which is followed by the empirical results and discussion of the findings. Finally, the paper ends with a concluding remark and limitations of the study. 


\section{Conceptual background and proposed hypotheses}

\subsection{Fundamentals of Service-dominant logic (SDL)}

Service-dominant logic is an emerging general theory of the market and society which transcends the traditional goods-services divide. It postulates that service, defined as the process of applying one's resources for the benefit of another actor, is the fundamental basis of economic exchange. All economies are service economies and goods are the distribution mechanism for service provision. In these economies, all economic actors are integrators of resources, of which operant resource is the fundamental source of strategic benefit. Actors utilize operant resources to act on other resources to create the outcome benefit (Vargo and Lusch 2016).

Besides its view on service and operant resource, SDL is also known as the theory of value co-creation. In this theory, value is defined as benefit or an increase in the well-being of a particular actor. It is always uniquely and phenomenologically determined by the beneficiary. Value is not solely created and delivered by the service provider, but co-created by multiple actors, always including the beneficiary. As such, the fulfillment of a service always requires the participation of different actors in which customers play an active role (Vargo and Lusch 2016). To this end, customer co-creation in a service involves cognitive and behavioral activities and interactions to integrate and transform resources into value for customers and other involved parties (Hau 2019). The co-creation activities can be required or voluntary (Dong and Sivakumar 2017). For a customer, these activities may be easy, simple, or challenging that requires certain level of capability and effort (Sweeney et al. 2015). They may occur in the direct interaction platform between the customer and service provider, or happen independently within the customer's own sphere (Gronroos and Voima 2013).

\subsection{Physician consultation}

In general, physician consultation, or the consultation provided by a physician to a patient, is described as a process of dialogue between a physician and a patient that leads to a decision (Humphreys 2002). During the dialogue, the physician exchanges information with patients about their health conditions or other concerns and advises the patient on what they should (or should not) do for the betterment of their health (Seiders et al. 2015). Physician consultation is an essential part of patient enablement (Fumagalli et al. 2015), which is the process for encouraging patients to take more responsibility in the management of their own health (Anderson et al. 2016). Therefore, the main function of physician consultation is to facilitate and develop patient's capability to self-manage their health (Hudon et al. 2010).

In the context of the current study, given that the unit of observation and analysis is a patient (not a physician), the term physician consultation is defined as the patients' perception about the extent of specialized knowledge and encouragement they receive from the physician through the consultation process. This definition emphasizes two points: Firstly, we focus only on the specialized knowledge on how 
to do the SMBG task and the motivation to do it. Secondly, the receipt of these two things is by patient from physician (which might be slightly different from the physician offers in the consultation process). It means that physician consultation is oriented toward the development of patient's own knowledge and capability to do the SMBG at home without the presence of health professionals (Giesler and Veresiu 2014). In the SDL view, healthcare professionals can encourage customer participation by providing them with intangible resources such as instruction of specialized knowledge and encouraging them to be more confident for performing participation activities (Virlee et al. 2020). This is done through their interaction behaviors, of which consultation is an essential part (Karpen et al. 2015).

By emphasizing its education aspect, physician consultation provides understanding (know-what, know-why) and advises patients on how to do (know-how) the cocreation behaviors. In practice, however, the education of patients is not without difficulties due to the significant gap of professional expertise between physicians and patients and the physical illness of patients (Berry and Bendapudi 2007). To this end, scholars have indicated that the effectiveness of the patient education process is depended on several factors, such as the clarity of the message or suggestion, the emphasis on the importance of the advice, the amount of time spent and frequency of the advice, the amount of information being provided, and the justification of the suggestions regarding the recommended behaviors (Seiders et al. 2015).

In the scope of this study, the consultation provided by a physician to a patient represents a form of the interaction behaviors of service frontliners. Through consultation, the physician creates opportunities to influence customers and the service outcomes (Gronroos 2011). Effective interaction with patients requires physicians to possess certain skills such as understanding patient's needs and personal situation, making social and emotional connections, assisting patients in developing knowledge and skills, and facilitating a coordinated service process (Karpen et al. 2015; Yi and Gong 2013). These interaction skills are supposed to extend the influence of physicians on patients beyond the joint sphere to the patients' own co-creation sphere (Gronroos and Voima 2013). Given that physician consultation is the interaction behavior of physicians, it is expected to have an impact on patient's participation behavior (Hau et al. 2017; Seiders et al. 2015). However, the influential mechanism and the extent to which physician's consultation affects patient adherence have yet been fully understood. To address this underexplored issue, this study proposes that physician consultation would exert its impact on patients' adherence to SMBG through building their capabilities and enhancing their self-efficacy to perform this co-creation task at home.

\subsection{Patient adherence to the use of SMBG as viewed from SDL perspective}

The adherence to the use of SMBG can be defined as the extent to which the patient has followed the advice of the service provider regarding to the use of SMBG (Seider et al. 2015). In the SDL view, it is a form of customer participation behavior in the service process (Dong and Sivakumar 2017; McColl-Kennedy et al. 2012). In the early stage of the service literature, this notion implies different levels of 
customer involvement in a service. Several terms were used to describe this phenomenon, such as do-it-yourself, partial employee, co-producer, productive resource provider, contributor, or competitor (Bitner et al. 1997). The involvement of customers in a service may encompass a variety of behaviors such as being present during the service delivery, providing information about their need and preference, or performing required activities for accomplishing the service (Bitner et al. 1997).

The contemporary SDL places more emphasis on the role of customers in a service. This paradigm views that the accomplishment of a service always requires the collaboration of engaged actors in which customers play the role of a service cocreator (Vargo and Lusch 2016). In the process, customers co-create the service by providing resources and integrating them into the consumption process through their active participation (Gronroos and Ravald 2011). Therefore, customer participation is viewed as the direct involvement of customers in the service creation from which they co-create value (Vargo and Lusch 2016). Accordingly, customer participation is defined as customer behaviors related to the creation and delivery of a service offering (Auh et al. 2007; Mustak et al. 2013). It relates to various activities and interactions to integrate and transform resources into benefits for customers and other parties involved (Hau 2019). The behaviors include information sharing, performing responsible activities, and giving voluntary feedback (Hau et al. 2017; Yi and Gong 2013). With these behaviors, customers contribute non-monetary resources, such as information, tacit knowledge, or competencies for the service outcomes (Mustak et al. 2013). These behaviors mainly occur in the service's joint sphere where the direct interaction between the customer and service frontliners takes place.

In healthcare service, several participation behaviors of patient are required because the service act is carried out on patient body (Anderson et al. 2013; Lee 2019). Without certain compulsory behaviors being accomplished by patients, the healthcare professionals cannot effectively produce and deliver the service outcome (Seiders et al. 2015). In addition to those compliance-with-basics behaviors (McColl-Kennedy et al. 2017), the extent of patient participation (i.e., substitutionary or voluntary behaviors) to the health service process has been found to positively associate with the level of the service success (Auh et al. 2007). In the specific context of this study, the use of SMBG device is recommended by the physician (i.e., service provider) as a measure to facilitate patient's substitutionary cocreation behavior being performed at home. Patients perform the self-test regularly and record the blood glucose in a real-time manner. The resultant information is important for monitoring the disease and is reported to the healthcare professional in immediate emergencies or in the next regular visit. In this circumstance, patient adherence to SMBG is represented by the extent to which a patient performs the self-test appropriately and goes on doing the task regularly as required. Prior studies have shown that despite the importance and necessity of such healthcare co-creation behaviors, the full adherence to SMBG is considered challenging and annoying due to factors such as pain, discomfort, frustration, lack of skill, time, or finance (MyQuyen et al. 2020; Wang et al. 2019). In such situation, without motivation, ability and effort of patients to be maintained properly; physicians may not fulfill the healthcare service satisfactorily (Spanjol et al., 2015). In other words, the service co-creation may not be completed successfully. 


\subsection{Customer capability for performing the SMBG}

An individual capability for performing a task refers to the possession of specialized knowledge or skill required to perform the task (Meuter et al. 2005). It describes the quality of being able to accomplish the task. In several instances, the term capability is used interchangeably with ability (e.g., Anderson et al. 2016; Tikkanen 2020). In fact, capability is a broader term than ability because the latter indicates only what we can actually do (i.e., have experienced), while the former encompasses both what we can actually do and what we could do if we are provided with a suitable opportunity. That is, the emphasis of the term capability is on the knowledge of what we are capable if we have the necessary resources (Vorhaus 2015).

From the resource view, capability is a kind of an individual's operant resource (Baron and Warnaby 2011). It is the potentiality that enables a person to enact an activity. It serves as the core operant resource which determines what and how other operant and operand resources are to be mobilized, interacted, and integrated for the execution of a task (Arnould et al. 2006). In other words, to perform a given task, customers need to possess appropriate capability that is the necessary understanding and know-how required specifically for the task. They also need to possess other operant resources (e.g., physical strength, social relations) and operand resources (e.g., materials and tools or devices) (Baron and Wanaby 2011). Of equal importance, they must want to perform the task. That is, they must hold a certain level of motivation (Meuter et al. 2005). The motivation may be sourced from intrinsic or extrinsic rewards. While intrinsic rewards refer to the anticipated pleasure or satisfaction with the task itself, extrinsic rewards come from the expected consequences being received upon completing the task (Ryan and Deci 2000).

From the knowledge view, an individual's capability for doing a task can be developed in different ways. She or he can acquire it through learning from other people (e.g., information, instruction, training), vicarious learning (e.g., interaction, observation, modeling), or own experience (i.e., doing the same or similar task in the past) (Stajkovic and Luthans 2003). The quality of the capability being developed is depended on several factors such as knowledge attributes (tacit vs. explicit, simple vs. complex), relationship with the knowledge source, the interaction mechanism, absorptive capacity, and learning effort of the individual as a learner (Song et al. 2018). It is these features and characteristics that imply various ways a service provider may influence their customer enablement process.

In the context of healthcare service co-creation, customer's capability to participate in the co-creation of the service refers specifically to their knowledge and/ or skills to perform required co-creation behaviors (i.e., SMBG test in this specific study). In this regard, healthcare scholars have used the term customer capabilization to reflect the process in which healthcare provider promotes, provides, and improves patients' capabilities to understand their condition and enable them to actively participate in the co-creation of healthcare service (Fumagalli et al. 2015). As such, the concept of customer capabilization is not only fit in the service co-creation perspective but also in line with the trend of customer responsibilization in transformative services including healthcare (Anderson et al. 2016; Shamir 2008). In essence, customer responsibilization entails a discourse and shift where social issues and 
tasks previously belonging to collective organizations become the responsibility of individual customers, who are expected to use market resources in handling these responsibilities (Anderson et al. 2016). To this end, the healthcare provider's capabilization to improve customer capability is a crucial component in the process of customer enablement, which is understood as the healthcare professional intervention aiming to recognize, support, and emphasize patient's capabilities to have control over their health and life (Hudon et al. 2010). It means helping patients develop their capability to perform certain co-creation behaviors (Giesler and Veresiu 2014; Tikkanen 2020).

\subsection{Customer self-efficacy for performing the SMBG}

Self-efficacy is defined as the belief of an individual on the level of control over an action or a life (Bandura 1997). It reflects the level of confidence about the possibility of accomplishing a task when the consideration focuses on the execution of the task itself, regardless of its consequential outcomes (Bandura 1997). In general, selfefficacy may vary significantly across individuals as a personal trait (trait-like selfefficacy), which is endowed naturally. It tends to affect all behavioral domains of an individual's life. Within an individual, self-efficacy may also vary as a contextual cognitive state (state-like self-efficacy) (Luthans and Youssef 2004). This state-like self-efficacy is resulted from the evaluation of the individual's ability to carry out a given task successfully (Hochhausen et al. 2007). For the purpose of this study, we focus more on the state-like self-efficacy, not withstanding the existence of trait-like self-efficacy (Schwarzer et al. 1997). Accordingly, self-efficacy is defined as one's confidence in his or her ability to mobilize the motivation, cognitive resources, and courses of action necessary to execute a specific course of action within a given context (Luthans and Youssef 2004).

As such, self-efficacy state can be contextually changeable (i.e., task-specific selfconfidence) and thus can be influenced and encouraged (Luthans et al. 2007). In this regard, Luthans and Youssef (2004), based on Bandura (1997), suggest various sources driving an individual's state of self-efficacy, including mastery experiences, vicarious learning or modeling, social persuasion, and psychological states. Mastery experiences are the first and the most important determinant of self-efficacy. Individuals who have succeeded at a task are likely to have a higher level of self-efficacy to complete similar tasks in the future. The second determinant of self-efficacy is vicarious learning or modeling. That is, observing another person's success at a particular task may enhance self-efficacy. The increase in self-efficacy is maximized when individuals see themselves as similar to the person they are observing. Next, social persuasion is the third driver of self-efficacy. An individual's self-efficacy will increase if he or she is persuaded by others about his or her ability to be successful at a particular task. The level of increase in self-efficacy is contingent on the source's credibility and previous relationship with the person. Finally, the level of self-efficacy is driven by the state of psychological arousal. People tend to perceive psychological arousals as signs of vulnerability and dysfunction. They would be in 
high level of self-efficacy to perform a task if they are not pre-occupied by emotional agitation (Stajkovic and Luthans 2003).

The present study relies on the above-mentioned antecedents of state-like selfefficacy to justify for the impacts of physician consultation and patient capability on patient self-efficacy, which will be presented in Sect. 3. Moreover, the adoption of state-like self-efficacy as advocated by Luthans and Youssef (2004) enables the operationalization and measurement of an individual's self-efficacy in a given context by the level of task-specific confidence (Grundy 1993).

\section{The proposed research model and hypotheses}

\subsection{The proposed research model}

To address the causal relations among the constructs under study, a structural model is developed and illustrated in Figure 1. This model is based on the stimulus-organism-response framework ( $\mathrm{S}-\mathrm{O}-\mathrm{R})$, which is the fundamental foundation of consumer behavior (Jacoby 2002). Accordingly, the receipt of physician consultation is seen as an external stimulus which stimulates the cognitive and affective process occurring inside the patient (i.e., it causes changes in the patient's capability and self-efficacy), leading to the patient's response (i.e., behavioral change in the level of adherence to SMBG). As depicted in this figure, physician consultation is proposed to positively affect patient capability (H1) and patient self-efficacy (H2). Patient capability is argued further to have a positive effect on patient self-efficacy (H3). Then, patient capability and patient self-efficacy are proposed to have positive effects on patient adherence to SMBG (H4 and H5). In this model, all four constructs are operationalized as first-order reflective constructs. The following sections will present the theoretical justifications for each of the proposed hypotheses.

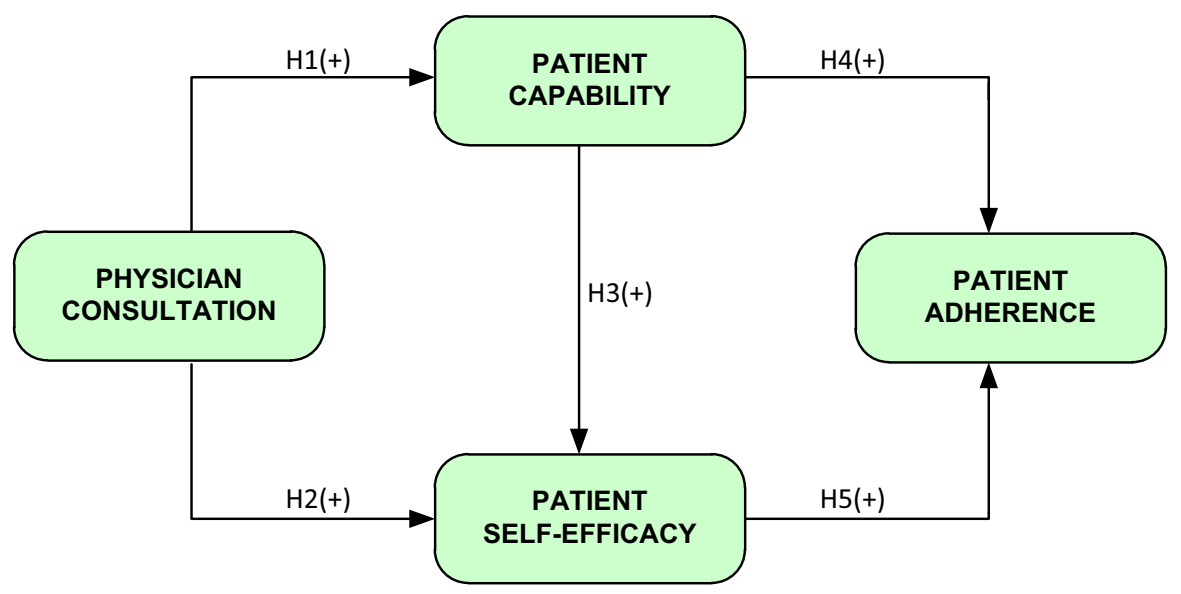

Fig. 1 The proposed research model 


\subsection{The effect of physician consultation on patient's capability}

Patient's capability in this case implies the knowledge and skill to perform the SMBG. When patients are recommended to do this task at home, they initially lack knowledge and skill to perform it (Seiders et al. 2015; Rose et al. 2009). From the personal resource perspective, specialized knowledge to perform the required task is a form of cultural resource that the patient is in deficiency ( $\mathrm{Ng}$ et al. 2019). In such a situation, the receipt of this resource from physician's consultation supplements this important cultural resource to perform the task. This is because the consultation (i.e., explaining, advising, and coaching) provides opportunities for patients to acquire knowledge and skill which are useful for the service (Hughes et al. 2018). If patients hold a suitable level of learning capability and the knowledge gap is not too high, they would acquire relevant knowledge (Lengnick-Hall et al. 2000). The acquired knowledge will then be integrated with the patient's existing stock of knowledge and thereby transformed into a new set of operant resources necessary for carrying out the task properly (Virlee et al. 2020). Consequently, their specialized knowledge for co-creation behavior is improved. As this specialized know-how is a form of patient's cultural resource (Baron and Warnaby 2011), it enhances the patient's capability to carry out the SMBG at home. In other words, physician consultation will improve patients' capability.

The effect of physician consultation on patient's capability is further justified through its basic function of education (Anderson 1990). In general, customer education is defined as providing information to customers and to teach them how to co-operate with service providers in value co-creation (Wang et al. 2011). It can be viewed by a service firm as a socialization process that helps customers understand their expected contributive role in co-creation and thereby realize the full potential of the service they co-create (Bell and Eisingerich 2007). In this specific case, patient education involves physician's provision of information that is unique to a patient's health situation and suggestions related to SMBG (Burton 2002). Therefore, it is believed that physician consultation facilitates customer education and contributes to improve patient's capability through role clarity and ability (Wang et al. 2011). Through the consultation process, patients acquire new knowledge as a resource from physicians. Depending on their existing stock of knowledge and other operant resources, the resource integration occurs which creates new resources and improves the existing resources (Hughes et al. 2018). It is this improved operant resource that increases the capability of the patient toward the behavior under consideration.

It is, therefore, hypothesized that

H1 Physician consultation has a positive effect on the improvement of patient's capability.

\subsection{The effect of physician consultation on patient self-efficacy}

During the consultation process, patients receive information to explain and persuade them to adhere to SMBG. It is this verbal persuasion which is an important source of patient self-efficacy (Bandura 1997). With verbal persuasion, patients are 
convinced that they possess necessary capabilities to execute the action. Moreover, source credibility, knowledgeableness, and argument quality are properties associated with verbal persuasion, which determine the persuasiveness of a source (Van Beuningen et al. 2009). As explained by Bandura (1997), the level of self-efficacy will increase if he or she is persuaded by others about his or her ability to be successful at a particular task. Even when the persuasion message is not new to patients, the self-efficacy is still improved. To explain this effect, Van Beuningen et al. (2009) argue that our self-concepts are shaped by what we think we know. That is, we tend to compare our existing knowledge with the information received from other people. If we see that we know more about the task then we are likely to have high confidence to do it because our belief is reinforced.

In healthcare, the verbal persuasion being expressed by physicians through consultation would, therefore, increase the patient self-efficacy. Moreover, extent literature shows that physician consultation enables the open interaction between patients with service professionals, thereby facilitates the physician's ability to enact social elements such as trust, concern, and empathy with the patient (McColl-Kennedy et al. 2017). This aspect of social relationship building is an important aspect in healthcare service (Hau et al. 2017). In this regard, the extent of self-efficacy would even be higher because through the enhanced social relations, the patient would see that the source of persuasion (i.e., physician) is professionally credible and trustworthy (Stajkovic and Luthans 2003; Van Beuningen et al. 2009). In another aspect, in the specific case of physician consultation on SMBG, if the physician or his associate has some form of actual or visual illustration on a sample model or on the patient himself/herself, the level of patient self-efficacy would increase. This is because, according to Bandura (1997), observing another person succeed at a particular task enhances self-efficacy, and the increase in self-efficacy is maximized when individuals see themselves as similar to the person they are observing.

In support of the above reasoning, recent empirical studies (Fisher et al. 2011; Osborn et al. 2010) have found that patients who are well consulted by physicians about their disease and how to manage it would have more confidence to perform the recommended health behavior. A similar result has also been found by Temerak et al. (2018), who posited that consultation from professionals is essential to help patients to adapt regimens to their personal circumstances and motivate self-care behaviors over time.

Therefore, it is hypothesized that

H2 Physician consultation has a positive effect on patient self-efficacy.

\subsection{The impact of customer capability on customer self-efficacy}

An individual's capability for performing a particular task refers to the specialized knowledge of how to do it. For those who are novice to the task, this knowledge can be acquired through different sources such as training, instruction, observing other people's performance, or self-study (Van Beuningen et al. 2009). By these measures, any improvement of the specialized knowledge entails an increase in capability 
(Vorhaus 2015), which will then be translated into self-efficacy beliefs through cognitive processing (Dabholkar and Bagozzi 2002). For those who have performed the task before, their capacity would be improved by accumulating knowledge or skill from their own experience. In this situation, they are likely to have high level of self-efficacy to complete similar tasks in the future due to the effect of performance accomplishment (Bandura 1997).

From the personal resource view, an increase in the capability toward a task entails a transformation of an individual's stock of operant resources (Hobfoll et al. 2018). It is the transformed set of operant resources that enables the individual to enact the activities related to the task. Its new configurations of operant resources serve as the basis to figure out what and how other operant and operand resources are to be mobilized, interacted, and integrated for the execution of a task (Arnould et al. 2006). Consequently, they would perceive that their capability is commensurate with what the task requires. According to the personality-job fit theory (Kristof-Brown et al. 2005), when individuals perceive that there is a high level of demands-abilities fit, they are more confident and competent in fulfilling their tasks. That is, their level of self-efficacy increases.

Applying these theoretical justifications to the context of SMBG adherence, we propose that

H3 Patient's capability has a positive effect on the extent of self-efficacy.

\subsection{The impact of customer capability on SMBG adherence}

The impact of customer capability on actual co-creation behavior (i.e., adherence to $\mathrm{SMBG}$ ) is justified through the increased state of customer readiness for co-creation, which is described as a state in which a consumer is prepared and likely to perform a co-creation behavior (Wang et al. 2011). Previous works have indicated that customers' readiness encompasses three key components that enable them to perform a co-creation task. They are task clarity (i.e., knowing clearly what to do), capability (i.e., knowing clearly how to do), and motivation (i.e., knowing clearly why to do) (Meuter et al. 2005; Wang et al. 2011). As such, it is reasonable to argue that customers with high level of capability are in a more ready state for action because they know well about how to do the task, thereby are more likely to perform the actual co-creation behavior (Chan et al. 2010).

The causal relationship between customer capability and the extent of his or her actual adherence to SMBG can also be justified by the theory of demands-abilities fit (Kristof 1996). Accordingly, when customers perceive that there is a high level of fit between a task demands and their abilities to fulfill it, they are more likely to take the action. In other words, if they estimate that their capability is commensurate with what the task requires, they would feel more competent in fulfilling the task with little effort (Kristof-Brown et al. 2005).

The other line of reasoning for the proposed relationship between customer capability and the actual participation behavior in the SMBG is based on the resource conservation theory. This theory postulates that much of human behavior is based on 
the evolutionary need to conserve resources for survival, which is central to human behavioral genetics (Hobfoll et al. 2018). As such, if customers realize that there is a significant demand-capability discrepancy, they are less motivated to do the related action because their effort would be at a high risk of failure. That is, when patients feel that they have low capability to perform the task, they would incline not to embark on it for avoiding resource loss.

Based on the above theoretical justifications, we propose that

H4 Patient's capability has a positive effect on the extent of SMBG adherence.

\subsection{The impact of customer self-efficacy on SMBG adherence}

Literature has indicated that an individual's self-efficacy affects whether the behavior will be initiated, how much effort will be expended, and how long it will be sustained in the face of obstacles and aversive experiences (Bandura 1997). In other words, self-efficacy is argued to have a significant positive impact on the executing and sustaining a task. This impact can be explained through motivational and affective mechanisms (Luthans and Youssef 2004). The motivational explanation of the impact relies on the attribution theory, the expectancy-value theory, and selfdetermination theory (Stajkovic and Luthans 2003). Firstly, according to the attribution theory (Weiner 1985), individuals judge the success or failure of a task (e.g., doing the SMBG) based on their causal attributions. If they anticipate the success of the task, they would credit that outcome to their capability and effort. That is, they believe that their capability to accomplish the task is the cause of that outcome. This attribution of self-efficacy will then have a positive effect on their motivation to do the task (Bandura 2005). Secondly, the expectancy-value theory (Vroom, 1964) postulates that when individuals expect that a certain task (e.g., doing the SMBG) would result in a desired outcome or benefit, they would have an extrinsic motivation to do it. However, if they lack self-efficacy about their ability to perform the task, they may judge that the task is difficult, challenging, or needs an enduring effort to accomplish and the motivation may fade away. They may opt not to perform it to save resources (Inzlicht et al. 2018) or they may decide to abandon the task after starting it for some time (My-Quyen et al. 2020). In contrast, if they have a high level of self-efficacy, they are confident that they can mobilize the resources to embark on the task (Luthans and Youssef 2004). Then, after initiating the action, they monitor and attend to cues associated with their performance. If they have a high level of self-efficacy, they will see that the ongoing performance is rewarding and gratifying, which reinforces and sustains their motivation to accomplish the task (Otto and Daw 2019). Thirdly, according to the self-determination theory (Ryan and Deci 2000), if people have a need to prove that they have the autonomy and competence to do a task, they would have an intrinsic motivation to execute the task. That is, the belief of competence (i.e., self-efficacy) to accomplish the task would drive people to execute the SMBG task (Dabholkar and Bagozzi 2002).

In addition to the motivational mechanism, the affective mechanism to explain the impact of self-efficacy on the active participation on SMBG lies in the strong 
association between self-efficacy and positivity (Luthans et al. 2008; Peterson 2000). As mentioned above, self-efficacy is a form of a positive psychological resource which reflects "who you are." Together with hope, optimism, and resiliency, self-efficacy determines the extent of an individual's positivity (Luthans and Youssef 2004), which in turn has shown to have a significant impact on behavior (Luthans et al. 2008). This line of argument has been empirically supported by Rose et al. (2009), who find a strong link between self-efficacy and diabetes self-management, with higher levels of self-efficacy promoting healthy diet, physical activities, and blood glucose self-monitoring. In contrast, patients with little self-efficacy (i.e., low level of belief in their ability to manage their diabetes) abdicate their responsibility for self-monitoring of blood glucose. Some other studies have also shown evidence on the influence of self-efficacy on patients' adherence to physicians' advice (e.g., Osborn et al. 2010; Seiders et al. 2015).

Therefore, it is hypothesized that

H5 Patient's self-efficacy has a positive effect on the extent of SMBG adherence.

\section{Method}

\subsection{Empirical setting-diabetes patient adherence to SMBG}

The research was conducted in the healthcare sector which has been identified as one of the top service research priorities (Ostrom et al. 2015). Specifically, the study focused on diabetes patients in Vietnam. According to the International Diabetes Federation (2020), Vietnam is among countries having the highest and fastest growing rate of diabetes in Southeast Asia region. Statistics from International Diabetes Federation (2020) estimate that approximately 5.8 million people in the country ( $6 \%$ of the population) currently suffer from this disease. However, a high proportion of them (about 65\%) are not aware of having diabetes mellitus. Most of them are low-income people living in rural areas who are unlikely to afford visiting healthcare professionals regularly for coping with this chronic disease (Ngoc et al. 2020). This situation makes diabetes being projected as one of the top seven diseases leading to death in Vietnam by 2030 (Mathers and Loncar 2006). In contrast, about 3.8 million people (about $35 \%$ of the cases) have been diagnosed diabetes. The majority of these people live in urban areas (Ngoc et al. 2020). Many of them are recommended by physicians to perform the SMBG at home using a handheld device. In the literature, the shift of this service task from healthcare professionals to healthcare customers is referred to as customer responsibilization (Anderson et al. 2016). From the service cocreation perspective, this is an important co-creation task required for customers to do in the service co-creation process. In this case, a patient's responsibility to adhere to the use of SMBG is important in coping with this disease. 


\section{Research design and data collection}

Data were obtained from diabetes patients at outpatient endocrinology departments in 15 hospitals in Hanoi, Ho Chi Minh City, and Da Nang, the three biggest cities in Vietnam. Patients were approached conveniently for a face-to-face interview at the waiting lounges (with the prior approval of hospital administrators). Copies of a structured questionnaire were delivered and collected after completion, which took about 10 to $12 \mathrm{~min}$. Data collectors were 9 students who were trained carefully before the survey. The questionnaire was firstly prepared in English and then translated to Vietnamese by two university academics following the collaborative translation technique (Douglas and Craig 2007). This direct collaboration in the translation allows mismatched issues being discussed among the translators and the researchers, resulting in the Vietnamese version being adjusted satisfactorily. The questionnaire was then pretested qualitatively to ensure its relevance and clarity to respondents. Minor adjustments were then made in the consultation of the mentioned translators.

To fit the contextual setting in this study, the survey questionnaire was designed specifically to measure the perception of patients about their own condition, diabetes, and the self-assessment of their receipt of specialized knowledge and encouragement from physician consultation, as well as their capability, self-efficacy, and level of adherence. In terms of construct measurement, all scales to measure the extent of the constructs under study were adopted from prior studies (see Table 1). Perceived physician consultation was measured by 5 items adopted from Rose et al. (2009). SMBG adherence was measured by 3 items adopted from Toobert et al. (2000) and Hansen et al. (2009) characterized by the frequency of actions. Scale items measuring patient capability ( 5 items) were borrowed from Fisher et al. (2011). Self-efficacy was measured through the

Table 1 Sample characteristics $(\mathrm{N}=391$ cases $)$

\begin{tabular}{llllll}
\hline Characteristics & Frequency & $\%$ & Characteristics & Frequency & $\%$ \\
\hline Gender: & & & Type of diabetes: & \\
Male & 149 & 38.1 & Type I & 77 & 19.7 \\
Female & 242 & 61.9 & Type II & 82 & 59.3 \\
Total & 391 & 100 & Not sure & 391 & 100 \\
& & & Total & & 39.1 \\
Age group: & & & Type of treatment: & 53 \\
30-45 & 101 & 25.8 & Insulin injection & 222 & 4.1 \\
46-65 & 218 & 55.8 & Oral medicine & 16 & 100 \\
66 or above & 72 & 18.4 & Diet \& exercise & 391 & \\
Total & 391 & 100 & Total & \\
City of Living: & & & & \\
Hanoi & 104 & 26.6 & & \\
Da Nang & 83 & 20.9 & & \\
Ho Chi Minh City & 204 & 52.4 & & \\
Total & 391 & 100 & & \\
\hline
\end{tabular}


level of task-specific confidence represented by 4 items adopted from Grundy (1993). Five-point Likert-type rating format was used to score responses.

\section{Results}

\subsection{Sample characteristics}

The sample consists of 391 usable cases. Among them, 204 respondents (or 52.4\%) were living in Ho Chi Minh City, 104 (or 26.6\%) were in Hanoi, and 83 (or 20.9\%) were in Da Nang city. In terms of gender, 242 patients (or 61.9\%) were female and 149 (or $38.1 \%$ ) were male, indicating that the sample is slightly inclined to female respondents. For age distribution, more than one half of respondents (218 cases or 55.8\%) were in the age of 46 to 65 . Other age groups include 30 to 45 (101 cases or 25.8\%) and above 65 (72 cases or 18.4\%). These figures are in line with the reported situation by IDF (2020). Much more patients suffer from diabetes type II (232 cases or 59.3\%) than type I (77 cases or 19.7\%). Specifically, a significant number of respondents in the sample (82 cases or $21 \%$ ) reported that they did not know clearly about their diabetes type, implying that these patients have limited knowledge about their disease. When being asked about the treatment method, 222 respondents (or 56.8\%) reported that they were using oral medicine, while 153 respondents (or 39.1\%) were using insulin injection, and 16 (or $4.1 \%$ ) said that they were just on a diet and exercise. These statistics of patient's demographics are in line with the real situation of diabetes in Vietnam and many other countries, according to IDF (2020). Moreover, the data are diverse enough for use in this variance-based research for hypothesis testing (Calder et al. 1981). It is therefore concluded that the sample is appropriate for further analysis.

\subsection{Test of common method variance (CMV)}

This study relies on a single source of data using survey approach. Therefore, it is necessary to test the common method bias. Firstly, CMV was assessed by conducting the Harman's single-factor method (MacKenzie and Podsakoff 2012), which revealed significantly low fit indices: Chi-square $=1231.6 ; \mathrm{dF}=77 ; \mathrm{CFI}=0.63 ; \mathrm{TLI}=0.56$; RMSEA $=0.20$. Additionally, the marker-variable technique was applied (Lindell and Whitney 2001). The marker variable was "I am always sad because of not being rich," which was theoretically uncorrelated with other variables in the study. Statistical results showed that the marker variable had no significant correlation with 10 out of 17 items in the study ( $r=0.007-0.039 ; p=0.209$ to $0.887>0.05$ ). These results indicate that $\mathrm{CMV}$ is not a problem and the estimated relationships in this study were not biased by the presence of CMV.

\subsection{Scale assessment and refinement}

Firstly, an exploratory factor analysis (EFA) was applied to all 17 items measuring 4 constructs for a preliminary assessment. The analysis yielded 4 factors 
which were in line with the designated constructs. As shown in Table 2, each of 17 items loaded highly (between 0.55 and 0.98 ) on its designated factor. No occurrence of cross-loading was detected in the results. Thus, in this preliminary assessment, it is concluded that the 4 scales including 17 items achieved the criteria for unidimensionality, convergent validity, and discriminant validity. Moreover, the Cronbach's alpha (Table 3) ranged from 0.82 to 0.88 which indicated the reliability of the scales.

Next, confirmatory factor analysis (CFA) was conducted on 17 items measuring 4 constructs in the model. The result indicated that 3 items need to be eliminated (due to high error covariance) to ensure the fitness of the full measurement model with the data. Among the eliminated items, one measures physician consultation, one measures patient capability, and one measures patient self-efficacy. The refined CFA yielded the following fit indices: Chi-square $=225.53 ; \mathrm{dF}=71$; Chi-square $/ \mathrm{dF}=3.18 ; \mathrm{TLI}=0.94 ; \mathrm{CFI}=0.95$; $\mathrm{RMSEA}=0.07$. The standardized factor loadings of qualified items are shown in Table 3 which range from 0.64 to 0.94 , all above 0.50 . The average variance extracted (AVE) of scales ranges from 0.58 to 0.70 , which all exceed 0.50 . These results indicate satisfactory convergent validity of scales. The composite reliability (CR) of scales ranges from 0.83 to 0.89 , which are satisfactory as suggested by Kline (1998). The squared correlation coefficients of 6 pairs of constructs (Table 4) are smaller than their respective AVEs, which imply that discriminant validity of all scales is achieved (Fornell and Larcker 1981).

Table 2 Factor loading and cross-loading of items (EFA results)

\begin{tabular}{lrrrr}
\hline Measurement item & \multicolumn{2}{l}{ Construct } & & \\
\cline { 2 - 5 } & $\begin{array}{l}\text { Physician } \\
\text { consultation }\end{array}$ & Patient capability & Patient self-efficacy & Patient adherence \\
\hline Consult1 & $\mathbf{. 6 2 8}$ & -.034 & .153 & .121 \\
Consult2 & $\mathbf{. 8 5 9}$ & -.019 & -.101 & .075 \\
Consult3 & $\mathbf{. 8 5 8}$ & -.027 & .029 & -.007 \\
Consult4 & $\mathbf{. 7 9 4}$ & .036 & .016 & -.072 \\
Consult5 & $\mathbf{. 8 3 9}$ & .024 & .010 & -.082 \\
Capab1 & -.109 & $\mathbf{. 5 4 8}$ & .216 & .114 \\
Capab2 & -.125 & $\mathbf{. 6 2 9}$ & .221 & -.063 \\
Capab3 & .008 & $\mathbf{. 8 6 4}$ & -.126 & .010 \\
Capab4 & .032 & $\mathbf{. 8 1 6}$ & .040 & .040 \\
Capab5 & .204 & $\mathbf{. 6 7 9}$ & -.078 & .025 \\
Selfeff1 & -.104 & .069 & $\mathbf{. 7 2 1}$ & .023 \\
Selfeff2 & .034 & -.016 & $\mathbf{. 8 0 2}$ & .008 \\
Selfeff3 & .155 & .067 & $\mathbf{. 5 8 3}$ & -.087 \\
Selfeff4 & .097 & -.004 & $\mathbf{. 8 3 7}$ & $\mathbf{. 8 2 1}$ \\
Adherence1 & .026 & -.019 & -.050 & $\mathbf{. 9 8 1}$ \\
Adherence2 & -.038 & -.097 & .061 & $\mathbf{. 6 6 2}$ \\
Adherence3 & .009 & .208 & -.048 & \\
\hline
\end{tabular}


Table 3 Scale items and standardized loadings (CFA results)

Construct and item

CFA std. loading

Physician consultation: Cronbach's alpha $=0.88, \mathrm{CR}=0.89, \mathrm{AVE}=0.66$

Physician tells me about the risk of uncontrolled blood glucose

Physician explains me about the self-test data

Physician instructs clearly how to do the self-test of blood glucose

0.86

Physician explains why I need to do the self-test of blood glucose

Eliminated

Physician encourages me to do the self-test regularly

Patient capability: Cronbach's alpha $=0.84, \mathrm{CR}=0.85, \mathrm{AVE}=0.58$

I know how to verify the test strips before doing test

Eliminated

I can comfortably prick finger for blood sample

0.64

I rarely receive error message due to incorrect testing

I am able to perform easily the self-test of blood glucose

When reading the result, I know if I need to do the test again

Patient self-efficacy: Cronbach's alpha $=0.82, \mathrm{CR}=0.83, \mathrm{AVE}=0.62$

I am confident of being able to do the test at any time and place

I am confident in doing blood test for myself

Eliminated

I use the self-test result to discuss confidently with my physician

I can assess my disease progress through the self-monitoring test

Patient adherence to SMBG: Cronbach's alpha $=0.87, \mathrm{CR}=0.87, \mathrm{AVE}=0.70$

Compliance to blood glucose testing (not at all-completely)

Frequency of self-test per week on average

Number of self-tests in the last two weeks on average

0.80

\subsection{Structural model estimation and hypothesis testing}

The structural model was then estimated by applying CB-SEM (AMOS software) with maximum likelihood method. The estimation resulted in a good fit: Chisquare $=227.24 ; \mathrm{dF}=72 ; \mathrm{CFI}=0.95 ; \mathrm{TLI}=0.93 ; \mathrm{RMSEA}=0.07$. No Heywood case was detected. The test of normality of variables showed that kurtosis values ranged from -1.07 to -0.14 and skewness values ranged from -0.63 to +0.17 , which

Table 4 Discriminant validity of scales

\begin{tabular}{lllll}
\hline & $\begin{array}{l}\text { Physician consul- } \\
\text { tation }\end{array}$ & Patient capability & $\begin{array}{l}\text { Patient self- } \\
\text { efficacy }\end{array}$ & $\begin{array}{l}\text { Patient } \\
\text { adher- } \\
\text { ence }\end{array}$ \\
\hline $\begin{array}{l}\text { Physician consultation } \\
\text { Patient capability }\end{array}$ & 0.66 & 0.28 & 0.58 & \\
Patient self-efficacy & 0.44 & 0.49 & 0.62 & 0.70 \\
Patient adherence & 0.14 & 0.23 & 0.21 & \\
\hline
\end{tabular}

Values in the lower triangular region represent the squared correlation coefficients

Values in the diagonal represent the average variance extracted (AVE) 
indicated that the normality of variables is not a concern in this analysis (Lei and Lomax 2005).

The standardized path coefficients (Table 5) representing five hypotheses from H1 to H5 were significant at $p<0.05$. Therefore, all five hypotheses were supported by the data. Specifically, physician consultation has been found to have significant positive effects on patient capability (beta $=0.53, p=0.001$ ), thus supporting H1. Physician consultation also has a positive effect on patient self-efficacy (beta $=0.41$, $p=0.004)$, supporting H2. Hypothesis H3 is supported with beta $=0.48(p=0.001)$, meaning that patient capability has a positive effect on patient self-efficacy. The total effect of physician consultation on patient self-efficacy (direct effect plus indirect effect via patient capability) is substantial with beta $=0.67(p=0.003)$. Then, patient capability has a positive effect on patient adherence to SMBG, supporting H4 with beta $=0.31(p=0.004)$. Patient self-efficacy has a positive effect on patient adherence to SMBG, supporting H5 with beta $=0.25(p=0.009)$. These statistics yield a significant total effect of patient capability on patient adherence to SMBG (direct effect plus indirect effect via self-efficacy) with beta $=0.43(p=0.002)$. Further analysis of the research model has resulted that physician consultation has no significant direct effect on patient adherence (beta $=0.10, p=0.21>0.05$ ). Therefore, physician consultation affects patient adherence indirectly only through the enhancement of patient capability and self-efficacy (beta $=0.33, p=0.001)$.

\section{Discussion}

The empirical findings of this study indicate that physician consultation has substantial effects on both patient capability and self-efficacy. Furthermore, the level of patient's adherence to SMBG is significantly affected by patient capability and patient self-efficacy. Between these two factors, patient capability is found to have a stronger effect than self-efficacy. The former has a stronger direct and indirect impacts on adherence than the latter. This finding implies the necessity of patient capability as an important operant resource for co-creation behavior in

Table 5 Standardized estimates and hypothesis testing (sample size $=391$ cases)

\begin{tabular}{|c|c|c|c|c|c|c|c|c|}
\hline & Hypothesis & & & & Std. Coeff & $p$ value & $t$ value & Test result \\
\hline $\mathrm{H} 1$ & $\begin{array}{l}\text { Physician con- } \\
\text { sultation }\end{array}$ & $\rightarrow$ & & $\begin{array}{l}\text { Patient } \\
\quad \text { capabil- } \\
\text { ity }\end{array}$ & 0.53 & 0.001 & 10.79 & Supported \\
\hline $\mathrm{H} 2$ & $\begin{array}{l}\text { Physician con- } \\
\text { sultation }\end{array}$ & $\rightarrow$ & Patient self-efficacy & & 0.41 & 0.004 & 6.27 & Supported \\
\hline $\mathrm{H} 3$ & $\begin{array}{l}\text { Patient capabil- } \\
\text { ity }\end{array}$ & $\rightarrow$ & Patient self-efficacy & & 0.48 & 0.001 & 8.15 & Supported \\
\hline $\mathrm{H} 4$ & $\begin{array}{l}\text { Patient capabil- } \\
\text { ity }\end{array}$ & $\rightarrow$ & Patient adherence & & 0.31 & 0.004 & 3.34 & Supported \\
\hline H5 & $\begin{array}{l}\text { Patient self- } \\
\text { efficacy }\end{array}$ & $\rightarrow$ & Patient adherence & & 0.25 & 0.009 & 2.64 & Supported \\
\hline
\end{tabular}


this professional service. Meanwhile, self-efficacy is the second determinant of patient adherence. It represents a psychological resource which evokes a patient's motivation to perform the task. Moreover, a patient's state of self-efficacy toward the SMBG task can be fostered by an internal source (perceived capability) as well as an external source (physician consultation). Statistics further indicates that physician consultation does not have a direct effect on patient adherence to SMBG. It only affects indirectly by increasing the capability and self-efficacy of the patient.

By these findings, this study contributes to the literature in three aspects. The first contribution relates to the inherent feature of inseparability and high contact of many services including healthcare. In many instances, these characteristics cause difficulties and challenges for both providers and customers in the service process. Especially in the COVID-19 pandemic, these characteristics seriously affect the normal performance of many service industries worldwide. This is because any forms of face-to-face contact between co-creation actors can lead to serious illness or death (Berry et al. 2020). In this situation, the findings of this study promote a possible measure to increase the separability and decrease direct contacts in transformation services. This solution can be implemented by an "untact" strategy in services (Lee and Lee 2020). This strategy encourages service providers to apply technologybased innovations characterized by spatial flexibility and social outreach into the service procedure (Heinonen and Strandvik 2020).

The second theoretical contribution of this study is regarded to the development of SDL theory. This study provides a case to elucidate that the joint sphere of the service co-creation can be extended spatially (Gronroos and Voima 2013). Beyond the direct interaction, service frontliners can still foster customer participation by providing their operant resources through consultation activities. In their absence, customers can perform the co-creation by utilizing frontliner's resources which have already been integrated into customers' own resource stock. By this process, the extended co-creation platform opens more opportunities and flexibilities for the better co-creation between service providers and customers. Moreover, the result shows that physician consultation as an interaction behavior has its single role in activating customer participation, but not in enhancing co-creation value. This finding provides insights to consolidate that the interaction behaviors of frontliners in a value cocreation process can be for the purpose of value enhancement or participation activation, as specified by Hau et al. (2017).

The third contribution of this study is specifically for the healthcare service. It adds more insights into the idea of shifting part of the healthcare responsibility to customers (Anderson et al. 2016). This trend has raised some social concerns and challenges because customers vary substantially in terms of health service literacy (Davey and Gronroos 2019). They are certainly unable to decently complete the cocreation job without relevant supports from health service providers. In this regard, our findings suggest that the shift of responsibility to customers is possible, but must be coupled with appropriate measures to improve customer capability through activities like consultation, education, enablement, or capabilization. This possibility helps reduce the inherent inseparability and increase the flexibility of the service procedure. 
In terms of managerial implications, the findings of this study evoke some suggestions for health service providers. Firstly, healthcare providers should take into account the advantage of technology innovations (Hong and Lee 2018) to delegate certain tasks to customers, thereby create more options for them (Gustafsson et al. 2020). Once customers are enabled (e.g., through consultation) by service professionals, they can choose the most convenient and suitable mode of service conduct for themselves. This personalized measure may not only save the service cost but also increase the service value. However, healthcare providers should be selective in deciding what task to be delegated to customers, so that it is not too far beyond the customer capability and resources. Secondly, physicians play an important role in controlling the service performance. Besides improving their professional skills, physicians should be trained on how to perform the consultation with patients effectively. The knowledge and skill to be trained may involve what and how to improve the patient-specialized literacy (Davey and Gronroos 2019) and how to encourage patient to be more confident and more active in the health co-creation process.

\section{Conclusion}

Based on the context of SMBG test, this study explores a health service issue in which patients are recommended by professionals to perform a self-test at home following their consultation during the treatment process. Although the real-time test data are important for the treatment, a significant number of patients do not accomplish this responsible task. To understand this problem, we attempt to get insights into two general issues: The first is how or in what way a physician's consultation can help patients to adhere to SMBG. The second is what factors of patients affect the extent of patient's adherence. We approach the research problem from the view of the SDL coupled with customer responsibilization perspective. Using a sample data collected from diabetes patients in Vietnam, this study finds that the success of this co-creation task is determined by the effort of healthcare professionals in their consultation process for enabling customers and the effort of customers to improve their capability and self-efficacy. In terms of generalizability, although the empirical findings are based on the specific context of SMBG test as a case in healthcare, the theoretical implications can be extended to those professional services that require multiple face-to-face contacts between customer and service professionals such as education or training.

While this study provides meaningful findings, limitations are unavoidable. Firstly, this study focuses only on the specific case of diabetic patients. Although this specific context provides an appropriate setting for testing and thereby illustrating the theoretical implications, the generalization of the findings should not be without caution. More studies in other contexts are, therefore, recommended. Secondly, although customer capability and self-efficacy have significant effect, these two determinants explain a moderate part of the variation of adherence. Thus, more explanatory factors should be considered in future studies, such as motivation, anticipated regret, and family support. Thirdly, given that capability can be developed through self-learning and experience, temporal factor may moderate the effect sizes 
under study. Other potential moderators may include the complexity of the task and/ or the availability or cost of the device associated with the assigned task. Moreover, physician consultation may also play a moderating role in the relationships under study. This study only focuses on its education aspect. More comprehensive study in the future might also take into account the other aspect of patients' health issues. Finally, the current study views self-efficacy as a task-specific state which is changeable within a person across different situations. Future study may investigate this construct as a trait property of customers. Exploring the role of the factors mentioned above would facilitate our full understanding of the phenomenon under study.

Acknowledgements This research is funded by Vietnam National University Ho Chi Minh City (VNUHCM) under grant number NCM2019-20-02.

\section{References}

Anderson LA (1990) Health-care communication and celected psychosocial correlates of adherence in diabetes management. Diabetes Care 13(Supplement 2):66-76

Anderson L, Ostrom AL, Corus C, Fisk RP, Gallan AS, Giraldo M, Mende M, Mulder M, Rayburn SW, Rosenbaum MS, Shirahada K, Williams JD (2013) Transformative service research: An agenda for the future. J Bus Res 66(8):1203-1210

Anderson SJ, Jefferies JG, Ostrom AL, Baker CN, Bone SA, Downey H, Mende MN, Rapp JM (2016) Responsibility and well-being: Resource integration under responsibilization in expert services. J Public Policy Mark 35(2):262-279

Arnould EJ, Price LL, Malshe A (2006) Toward a cultural resource-based theory of the customer. In: Lusch RF, Vargo SL (eds) The new dominant logic in marketing: dialog, debate and directions. ME Sharpe, Armonk

Auh S, Bell SJ, McLeod CS, Shih E (2007) Co-production and customer loyalty in financial services. J Retail 83(3):359-370

Bandura A (1997) Self-efficacy: the exercise of control. Macmillan, New York

Bandura A (2005) The Evolution of social cognitive theory. In: Smith KG, Hitt MA (eds) Great minds in management. Oxford University Press, Oxford, pp 9-35

Baron S, Warnaby G (2011) Individual customers' use and integration of resources: Empirical findings and organizational implications in the context of value co-creation. Ind Mark Manage 40(2):211-218

Bell SJ, Eisingerich AB (2007) The paradox of customer education. Eur J Mark 41(5/6):466-486

Berry LL, Bendapudi N (2007) Health care: A fertile field for service research. J Serv Res 10(2):111-122

Berry LL, Danaher TS, Aksoy L, Keiningham TL (2020) Service safety in the pandemic age. J Serv Res. https://doi.org/10.1177/1094670520944608

Bettencourt LA, Ostrom AL, Brown SW, Roundtree RI (2002) Client co-production in knowledge-intensive business services. Calif Manage Rev 44(4):100-128

Bitner MJ, Faranda WT, Hubbert AR, Zeithaml VA (1997) Customer contributions and roles in service delivery. Int J Serv Ind Manag 8:193-205

Burton D (2002) Consumer education and service quality: conceptual issues and practical implications. J Serv Mark 16(2):125-142

Calder BJ, Phillips LW, Tybout AM (1981) Designing research for application. Journal of Consumer Research 8(2):197-207

Chan KW, Yim CK, Lam SS (2010) Is customer participation in value creation a double-edged sword? Evidence from professional financial services across cultures. Journal Marketing 74(3):48-64

Dabholkar PA, Bagozzi RP (2002) An attitudinal model of technology-based self-service: moderating effects of consumer traits and situational factors. J Acad Mark Sci 30(3):184-201

Davey J, Grönroos C (2019) Health service literacy: complementary actor roles for transformative value co-creation. J Serv Mark 33(6):687-701 
Dong B, Sivakumar K (2017) Customer participation in services: domain, scope, and boundaries. J Acad Mark Sci 45:944-965

Douglas SP, Craig CS (2007) Collaborative and iterative translation: An alternative approach to back translation. J Int Mark 15(1):30-43

Fisher WA, Kohut T, Schachner H, Stenger P (2011) Understanding self-monitoring of blood glucose among individuals with type 1 and type 2 diabetes: an information-motivation-behavioral skills analysis. Diabetes Education 37:85-94

Florc MV, Morató MJ, Rubio MG, Martínez MP (2018) Factors associated to adherence to blood glucose self-monitoring in patients with diabetes treated with insulin The dapa study. Endocrinología, Diabetes y Nutrición (English Ed) 65(2):99-106

Fornell C, Larcker DF (1981) Structural equation models with unobservable variables and measurement error: Algebra and statistics. J Mark Res 18(3):328-388

Fumagalli LP, Radaelli G, Lettieri E, Bertele P, Masella C (2015) Patient empowerment and its neighbours: Clarifying the boundaries and their mutual relationships. Health Policy 119(3):384-439

Giesler M, Veresiu E (2014) Creating the responsible consumer: Moralistic governance regimes and consumer subjectivity. Journal of Consumer Research 41(3):840-857

Gronroos C (2011) Value co-creation in service logic: a critical analysis. Mark Theory 11(3):279-301

Gronroos C, Ravald A (2011) Service as business logic: implications for value creation and marketing. J Serv Manag 22:5-22

Gronroos C, Voima P (2013) Critical service logic: making sense of value creation and co-creation. J Acad Mark Sci 41(2):133-150

Grundy SE (1993) The Confidence scale development and psychometric characteristics. Nurse Educ 18(1):6-9

Gustafsson A, Snyder H, Witell L (2020) Service innovation: A new conceptualization and path forward. J Serv Res. https://doi.org/10.1177/1094670520908929

Hansen D, Dendale P, Jonkers RAM, Beelen M, Manders RJF, Corluy L, Mullens A, Berger J, Meeusen $\mathrm{R}$, van Loon LJC (2009) Continuous low-to moderate-intensity exercise training is as effective as moderate-to high-intensity exercise training at lowering blood $\mathrm{HbA} 1 \mathrm{c}$ in obese type 2 diabetes patients. Diabetologia 52(9):1789-1797

Hau LN (2019) The role of customer operant resources in healthcare value creation. Serv Bus 13:457-478

Hau LN, Anh PNT, Thuy PN (2017) The effects of interaction behaviors of service frontliners on customer participation in the value co-creation: a study of health care service. Serv Bus 11(2):253-277

Heinonen K, Strandvik T (2020) Reframing service innovation: COVID-19 as a catalyst for imposed service innovation. J Serv Manage. https://doi.org/10.1108/JOSM-05-2020-0161

Hobfoll SE, Halbesleben J, Neveu JP, Westman M (2018) Conservation of resources in the organizational context: The reality of resources and their consequences. Annu Rev Organ Psych Organ Behav 5:103-128

Hochhausen N, Altmaier EM, McQuellon R, Davies SM, Papadopolous E, Carter S, Henslee-Downee J (2007) Social support, optimism, and self-efficacy predict physical and emotional wellbeing after bone marrow transplantation. J Psychosoc Oncol 25:87-101

Hong K, Lee D (2018) Impact of operational innovations on customer loyalty in the healthcare sector. Serv Bus 12:575-600. https://doi.org/10.1007/s11628-017-0355-4

Hudon C, St-Cyr Tribble D, Légaré F, Bravo G, Fortin M, Almirall J (2010) Assessing enablement in clinical practice: a systematic review of available instruments. J Eval Clin Pract 16(6):1301-1308

Hughes T, Vafeas M, Hilton T (2018) Resource integration for co-creation between marketing agencies and clients. Eur J Mark 52(5/6):1329-1354

Humphreys PC (2002) Effective Consultation with the External Customer, CPMR Discussion Paper No. 23. Dublin: Institute of Public Administration

International Diabetes Federation: https://idf.org/our-activities/advocacy-awareness/resources-and-tools/ 85:self-monitoring-of-blood-glucose-in-non-insulin-treated-type-2-diabetes.html. Accessed 24 Sept 2020

Inzlicht M, Shenhav A, Olivola CY (2018) The effort paradox: Effort is both costly and valued. Trends Cogn Sci 22(4):337-349

Jacoby J (2002) Stimulus-Organism-Response reconsidered: an evolutionary step in modeling (consumer) behavior. J Consum Psychol 12(1):51-57

Karpen IO, Bove LL, Lukas BA, Zyphur MJ (2015) Service-dominant orientation: measurement and impact on performance outcomes. J Retail 91(1):89-108

Kline RB (1998) Principles and practice of structural equation modeling. The Guilford Press, New York 
Kristof AL (1996) Person-organization fit: an integrative review of its conceptualizations, measurement, and implications. J Pers Psychol 49(1):1-49

Kristof-Brown AL, Ryan DZ, Erin CJ (2005) Consequences of individuals' fit at work: A meta-analysis of person-job, person-organization, person-group, and person-supervisor fit. Pers Psychol 58(2):281-342

Lee D (2019) Effects of key value co-creation elements in the healthcare system: focusing on technology applications. Serv Bus 13:389-417. https://doi.org/10.1007/s11628-018-00388-9

Lee SM, Lee D (2020) "Untact”: a new customer service strategy in the digital age. Serv Bus 14:1-22

Lei M, Lomax RG (2005) The effect of varying degrees of nonnormality in structural equation modeling. Struct Equ Modeling 12(1):1-27

Lengnick-Hall CA, Claycomb V, Inks LW (2000) From recipient to contributor: examining customer roles and experienced outcomes. Eur J Mark 34(3/4):359-383

Lindell MK, Whitney DJ (2001) Accounting for common method variance in cross-sectional research designs. J Appl Psychol 86(1):114

Luthans F, Youssef CM (2004) Human, social, and now positive psychological capital management: Investing in people for competitive advantage. Organ Dyn 33(2):143-160

Luthans F, Luthans KW, Luthans BC (2004) Positive psychological capital: Beyond human and social capital. Bus Horiz 47(1):45-50

Luthans F, Youssef CM, Avolio BJ (2007) Psychological capital. Oxford University Press, New York

Luthans KW, Lebsack SA, Lebsack RR (2008) Positivity in healthcare: relation of optimism to performance. J Health Organ Manag 22(2):178-188

MacKenzie SB, Podsakoff PM (2012) Common method bias in marketing: causes, mechanisms, and procedural remedies. J Retail 88(4):542-555

Mathers CD, Loncar D (2006) Projections of global mortality and burden of disease from 2002 to 2030. PLoS Med 3(11):442

McColl-Kennedy JR, Vargo SL, Dagger TS, Sweeney JC, Kasteren YV (2012) Health care customer value cocreation practice styles. J Serv Res 15(4):370-389

McColl-Kennedy JR, Snyder H, Elg M, Witell L, Helkkula A, Hogan SJ, Anderson L (2017) The changing role of the health care customer: review, synthesis and research agenda. J Serv Manag 28(1):2-33

Meuter ML, Bitner MJ, Ostrom AL, Brown SW (2005) Choosing among alternative service delivery modes: An investigation of customer trial of self-service technologies. J Mark 69(2):61-83

Moström P, Ahlén E, Imberg H, Hansson PO, Lind M (2017) Adherence of self-monitoring of blood glucose in persons with type 1 diabetes in Sweden. BMJ Open Diabetes Res Care 5(1):e000342. https:// doi.org/10.1136/bmjdrc-2016-000342

Mustak M, Jaakkola E, Halinen A (2013) Customer participation and value creation: a systematic review and research implications. Managing Service Quality: an International Journal 23(4):341-359

My-Quyen MT, Hau LN, Thuy PN (2020) Mindful co-creation of transformative service for better wellbeing. Serv Bus 14:413-437

Ng SC, Sweeney JC, Plewa C (2019) Managing customer resource endowments and deficiencies for value cocreation: complex relational services. J Serv Res 22(2):156-172

Ngoc NB, Lin ZL, Ahmed W (2020) Diabetes: What challenges lie ahead for Vietnam? Ann Glob Health 86(1):1-9

Osborn Y, Egede C, Leonard E (2010) Validation of an information-motivation-behavioral skills model of diabetes self-care. Patient Educ Couns 79(1):49-54

Osei-Frimpong K, McLean G, Wilson A, Lemke F (2020) Customer coproduction in healthcare service delivery: Examining the influencing effects of the social context. J Bus Res 120:82-93

Ostrom AL, Parasuraman A, Bowen DE, Patricio L, Voss CA (2015) Service research priorities in a rapidly changing context. J Serv Res 18(2):127-159

Otto AR, Daw ND (2019) The opportunity cost of time modulates cognitive effort. Neuropsychologia 123:92-105

Peterson C (2000) The future of optimism. Am Psychol 55(1):44-55

Rose V, Harris M, Ho MT, Jayasinghe UW (2009) A better model of diabetes self-management? Interactions between GP communication and patient self-efficacy in self-monitoring of blood glucose. Patient Educ Couns 77(2):260-265

Ryan RM, Deci EL (2000) Self-determination theory and the facilitation of intrinsic motivation, social development, and well-being. Am Psychol 55(1):68 
Schwarzer R, Bäßler J, Kwiatek P, Schröder K, Zhang JX (1997) The assessment of optimistic selfbeliefs: comparison of the German, Spanish, and Chinese versions of the general self-efficacy scale. Appl Psychol 46(1):69-88

Seiders K, Flynn AG, Berry LL, Haws KL (2015) Motivating customers to adhere to expert advice in professional services: a medical service context. J Serv Res 18(1):39-58

Shamir R (2008) The age of responsibilization: on market-embedded morality. Journal of Economy and Society $37(1): 1-19$

Song Y, Gnyawali DR, Srivastava MK, Asgari E (2018) In search of precision in absorptive capacity research: A synthesis of the literature and consolidation of findings. J Manag 44(6):2343-2374

Spanjol J, Cui AS, Nakata C, Sharp LK, Crawford S, Xiao Y, Watson-Manheim MB (2015) Co-production of prolonged, complex, and negative services. J Serv Res 18:284-302

Stajkovic AD, Luthans F (2003) Social cognitive theory and self-efficacy: implications for motivation theory and practice. In Porter LW, Bigley GA, Steers RM (eds) Motivation and work behavior. McGraw-Hill Irwin, pp 126-140

Sweeney JC, Danaher TS, McColl-Kennedy JR (2015) Customer effort in value cocreation activities: improving quality of life and behavioral intentions of health care customers. J Serv Res 18(3):318-335

Temerak MS, Winklhofer H, Hibbert S (2018) Facilitating customer adherence to complex services through multi-interface interactions: The case of a weight loss service. J Bus Res 88:265-276

Tikkanen H (2020) Characterizing well-being capabilities in services. J Serv Mark. https://doi.org/10. 1108/JSM-11-2019-0453

Toobert DJ, Hampson SE, Glasgow RE (2000) The summary of diabetes self-care activities measure: results from 7 studies and a revised scale. Diabetes Care 23(7):943-950

Van Beuningen J, De Ruyter K, Wetzels M, Streukens S (2009) Customer self-efficacy in technologybased self-service: Assessing between- and within-person differences. J Serv Res 11(4):407-428

Vargo SL, Akaka MA (2009) Service dominant logic as a foundation for service science: Clarifications. Serv Sci 1(1):32-41

Vargo SL, Lusch RF (2016) Institutions and axioms: an extension and update of service-dominant logic. J Acad Mark Sci 44(1):5-23

Virlee JB, Hammedi W, van Riel ACR (2020) Healthcare service users as resource integrators: investigating factors influencing the co-creation of value at individual, dyadic and systemic levels. J Serv Theory Pract 30(3):277-306. https://doi.org/10.1108/JSTP-07-2019-0154

Vorhaus JS (2015) Capabilities, human value and profound disability: Capability theory and its application to theatre, music and the use of humour. Disability \& Society 30(2):173-184

Vroom VH (1964) Work and motivation. Wiley

Wang W, Hsieh P, Yen HR (2011) Engaging customers in value co-creation: The emergence of customer readiness. International Joint Conf Serv Sci 135-139

Wang X, Luo JF, Qi L, Long Q, Guo J, Wang HH (2019) Adherence to self-monitoring of blood glucose in Chinese patients with type 2 diabetes: current status and influential factors based on electronic questionnaires. Patient Prefer Adherence 13:1269-1282

Weiner B (1985) An attributional theory of achievement motivation and emotion. Psychol Rev 92:548-573

Yi Y, Gong T (2013) Customer value co-creation behavior: Scale development and validation. J Bus Res 66(9):1279-1284

Yi WM, Van Wieren Jones EM, Hansen BK, Vora J (2019) The impact of self-monitoring blood glucose adherence on glycemic goal attainment in an indigent population, with pharmacy assistance. P\&T: Peer-Rev J Formul Manag 44(9): 554-559

Publisher's Note Springer Nature remains neutral with regard to jurisdictional claims in published maps and institutional affiliations. 